\title{
Harnessing innovation to improve global health
}

\author{
The Grandest Challenge: Taking Life-Saving \\ Science from Lab to Village \\ Dr. Abdallah Daar and Dr. Peter Singer \\ Doubleday Canada; 2011
}

$\mathrm{T}$ his book reminded me forcefully of the TED talk ${ }^{1}$ by Nigerian author, Chimananda Adichie who asks why outsiders focus on the single story of catastrophe in Africa even though there are many stories of creative and innovative work being done by Africans. I was ecstatic to find that in The Grandest Challenge Drs. Abdallah Daar and Peter Singer present both sides of the story in Africa and many developing regions, by focusing on successes rather than failures.

In eight engaging chapters, Daar and Singer describe their 10-year journey to understand and respond to the health care challenges, beginning with their personal experiences as immigrants. Daar, a public health expert born in Tanzania, was deeply affected by losing his sister to malaria. Singer, a bioethicist, born in Hungary, was affected by his childhood struggle to integrate after immigrating into Canada. Both eventually questioned the gap in health care between rich and poor and after joining forces at the University of Toronto in 1999, they set out to address this disparity by asking a fundamental question: How can we bring the innovations of the genomics revolution to developing nations and make the world a better place for all?

Daar and Singer begin their compelling case for harnessing innovation to improve global health by considering the work of Francis S. Collins, author of The Language of Life and head of the Human Genome Project. Daar explains how he became convinced that genomics could help develop better and less expensive drugs, vaccines and diagnostics. Singer examines how his

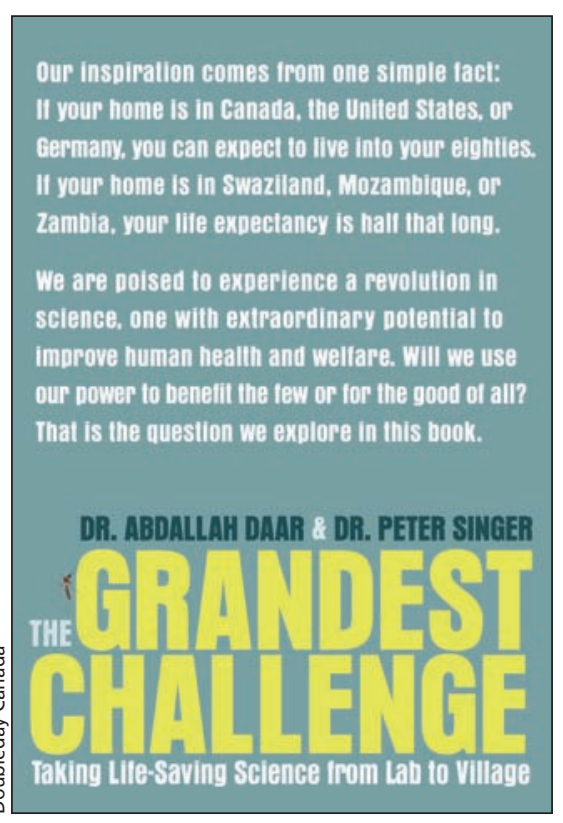

visits to hospitals and clinics in the developing world during the same period forced him to conclude that disparities are "the most immediate of all ethical challenges."

In considering possible remedies for this gap, the authors explore how science can be used equitably for the benefit of all humans. In fact, the good quality science being undertaken now in nations such as China and India, and the affordable technologies being developed there, are going to have a worldwide beneficial effect and may even help North Americans contend with an aging population and rising health care costs. For example, in India, a single organization, the Aravind Eye Care System does more than half the number of cataract surgeries performed annually in the United Kingdom, with equivalent clinical outcomes and at one percent of the cost. Whereas, the flow of innovation in the past was from rich to poor countries, often with less than satisfactory results, technology transfer is now being reversed as scientists and entrepreneurs in poor countries work against constraints that do not exist in rich countries and come up with affordable solutions that can be used anywhere.

Like many critics, Singer maintains that poor countries remain poor when no domestic ideas are turned into products, sold locally or exported, and that international aid often prevents nations from developing solutions to internal problems. Similarly, when ambitious, capable citizens of poor countries achieve some level of scientific training, immigration to a rich country is the next logical step, especially in Africa.

I was particularly interested in what The Grandest Challenge had to say about the misunderstood continent of Africa. The authors quote Vijay Mahajan, former dean of the Indian School of Business, who toured Africa, and discovered what few realize: that Africa is richer than many think, that the South Saharan countries could have gross domestic product growth rates approaching those of India and China, that the continent has a middle class of approximately 300 million people and that opportunities exist in all parts of the market.

Africa, in other words, is moving into a position where it can begin to solve its own health problems, rather than continuing to be passive recipients of medicine and money. Daar and Singer cite many examples of innovative scientists, both within Africa and within the diasporan community in Europe and North America, who are developing drugs and building institutions to address the burden of chronic diseases. Such initiatives, they say, are the best kind of "exit strategy for aid."

My own experience as an African diaspora physician who has made frequent trips to work on projects in Ethiopia, confirms what Daar and Singer say about harnessing the human imagination and compassion to solve fundamental problems worldwide. I too 
have seen many physicians and entrepreneurs who are making a difference. In Canada, Dr. Neil Turok, executive director of the Perimeter Institute of the University of Waterloo, Waterloo, Ontario, and creator of the African Einstein Initiative, is equipping African scientists in critical and foundational thinking in mathematics and science to help solve their unique scientific challenges. In the United States, Dr. Haile Debas, a diaspora physician and director of the University of California Global Health Institute, headed a consortium of American universities to establish an ethical framework of organized collective engagement, particularly in global health. These individuals and many others, demonstrate how commitment and passion can lead to universal benefits.
Are Daar and Singer overly optimistic about what can be achieved? Perhaps, but they have managed to map out a realistic, progressive agenda for the 21 st century, one that could see the global scientific community uphold the highest scientific standards while using technology to communicate in a way that allows everyone to innovate and participate in creating a better future.

I recommend this book highly and only wish it had appeared several years ago when many were insisting that physicians could not provide the leadership to take on the grandest challenges. By recognizing the dangers of a single story, and asking why a country is poor, we can leap ahead to support great scientists and entrepreneurs who are making progress in difficult circumstances. If we take life-saving science from the laboratory to the village, we'll do far more than charity ever could to lift countries out of poverty. And I dare say, that this might bring us closer to the Utopia Daar and Singer envision: A world where all children have a chance to grow up, live healthy lives, and be part of the pool of people that contribute to the betterment of humankind, no matter where they are born.

\section{Fikre Amare Germa MD}

Emergency physician

Brantford General Hospital

Brantford, Ont.

\section{Reference}

1. The danger of a single story: Chimamanda Adichie [lecture]. Oxford (UK): TEDGlobal; 2009. Available: http://blog.ted.com/2009/10/07/the_danger _of_a/ (accessed 2012 Feb. 1).

CMAJ 2012. DOI:10.1503/cmaj.111970 